\title{
How to assess technological developments in basic research?
}

\author{
Enabling formative interventions regarding sustainability, ethics, \\ and consumer issues at an early stage
}

Martin Möller, Cluster of Excellence livMatS, Plant Biomechanics Group, Botanic Garden of the University of Freiburg, Georges-Köhler-Allee 105, 79110 Freiburg (martin.moeller@livmats.uni-freiburg.de) (1) https://orcid.org/0000-0001-6608-1999 Philipp Höfele, Cluster of Excellence livMatS, Department of Philosophy, University of Freiburg (philipp.hoefele@philosophie.uni-freiburg.de) (1) https://orcid.org/0000-0002-8682-9965

Lisa Reuter, Cluster of Excellence livMatS, Institute of Psychology, University of Freiburg (lisa.reuter@livmats.uni-freiburg.de) (1) https://orcid.org/0000-0002-2757-0498 Falk J. Tauber, Cluster of Excellence livMatS, Plant Biomechanics Group, Botanic Garden of the University of Freiburg (falk.tauber@biologie.uni-freiburg.de) (1) https://orcid.org/0000-0001-7225-1472

Rainer Grießhammer, Cluster of Excellence livMatS, Faculty of Environment and Natural Resources, University of Freiburg (rainer.griesshammer@mail.indecol.uni-freiburg.de) (1) https://orcid.org/0000-0003-0201-1312

In an era of ever faster and more momentous technological development, both technology assessment and transdisciplinary interventions are in danger of structurally lagging behind the speed of innovation. This paper proposes a new tiered approach to technology assessment at low Technology Readiness Levels that enables a both rapid and concerted interdisciplinary science response to this Great Acceleration. Covering sustainability, ethics, and consumer issues, this approach encourages and enables the innovators themselves to conduct assessments embedded in the innovation process as early as possible. Suitable tools for early engagement that help facilitate development-integrated assessments are introduced and described. The design and use of these instruments in the field of basic research is illustrated using the Cluster of Excellence livMatS as an example.

\section{Wie lassen sich technologische Entwicklungen in der Grundlagenfor- schung bewerten?}

Möglichkeiten frühzeitiger gestaltender Einflussnahmen in Hinblick

auf Nachhaltigkeits-, Ethik- und Verbraucheraspekte

In einer Ära immer rascherer und folgenreicherer technologischer Entwicklungen laufen sowohl die Technologiebewertung als auch transdisziplinäre Interventionen Gefahr, strukturell hinter der Dynamik von Innovationen zurückzubleiben. In diesem Beitrag wird ein neuer gestufter Ansatz für die Technikfolgenabschätzung für niedrige Technology Readiness Levels vorgeschlagen, der eine schnelle und konzertierte interdisziplinäre Reaktion der Wissenschaft auf diese "große Beschleu-

This is an article distributed under the terms of the Creative Commons Attribution License CCBY 4.0 (https://creativecommons.org/licenses/by/4.0/)

https://doi.org/10.14512/tatup.30.1.56

Submitted: 19. 08.2020. Peer reviewed. Accepted: 07. 01.2021 nigung" ermöglicht. Dieser Ansatz, der Nachhaltigkeits-, Ethik- und Verbraucherfragen abdeckt, ermutigt und befähigt die Innovatoren, in den Innovationsprozess eingebettete Bewertungen so früh wie möglich selbst durchzuführen. Geeignete Instrumente für entwicklungsintegrierte Bewertungen werden vorgestellt und beschrieben. Die Konzeption und Anwendung dieser Instrumente im Bereich der Grundlagenforschung wird am Beispiel des Exzellenzclusters livMatS veranschaulicht.

Keywords: technology assessment, development-integrated, basic research, transdisciplinarity

\section{Introduction}

Since 1950 human activities have been influencing the Earth system with exponentially increasing speed. Part of this Great Acceleration (Steffen et al. 2011; Steffen et al. 2015) is the ever faster development and more consequential influence of technologies. While advanced technologies have helped economies in many countries to prosper, their usage has also provoked crises on a global scale, such as the massive decline in biodiversity or a permanent change in the climate (Rockström et al. 2009; Steffen et al. 2011).

One of the basic motivations of technology assessment (TA) is to deal with possible consequences of scientific and technological progress as early and comprehensively as possible, in order to enable formative interventions (Grunwald 2010). In particular, the Association of German Engineers (VDI) provides groundbreaking recommendations and rules for engineering 
sciences. According to VDI Guideline 3780 innovative technology assessment takes place when technical solutions are sought for existing problems or when initial solutions have already been developed, opening up the opportunity to influence the development process (VDI 2000). Another part of accompanying assessment of technologies and an essential tool for checking the suitability of a product is prototyping (Gibson et al. 2015). Early preliminary contact with a demonstrator or a prototype of a product allows for different perspectives and ideas for improvement.

Despite the already existing and established frameworks and tools mentioned above, both assessment and opportunity of intervention often systematically lag behind in the innovation process. A major reason is the fact that the evaluation merely accompanies the development without being involved in the relevant decisions during the development process. As part of a rapid and concerted re-action of science to the Great Acceleration, the assessment should be embedded as early as possible in the research and development (R \& D) process, ensuring the inclusion of societal challenges through a transdisciplinary approach.

With prospective TA and participatory TA, frameworks for evaluating R \& D of technologies at an early stage and involving civil society actors have been discussed and applied for several years (Abels and Bora 2013; Gleich 2013; Grunwald 2019; Owen et al. 2012). In order to implement these approaches in practice, however, instruments with suitable indicators and metrics are still needed, especially for monitoring and impact assessment of the factors defined in the frameworks mentioned above. it (livMatS 2020). Due to the cluster's focus on basic research in the field of material development, it is particularly well suited as a testbed for early, development-integrated assessment and as a practical check for the presented tools.

\section{Bringing assessment closer to the decisions in the R \& D process}

As part of the interdisciplinary cooperation and transdisciplinary inclusion of society, development-integrated assessments shall consider sustainability, ethical and consumer issues as central aspects right from the start. In the following, we describe three major principles in this respect: (1) mutual understanding of semantics, (2) early warnings and early encouragement, (3) embracing societal responsibility as part of the freedom of research.

\section{Mutual understanding of semantics}

A development-integrated assessment requires a precise understanding of the concepts utilized by the participating actors. Given the difficulty of establishing a common semantic base between different research fields (MacLeod 2018), tools have already been developed to address this issue (Warschat et al. 2015). A precise use of certain terms and thus a mutual understanding of semantics related to the different subject areas is, first of all, the prerequisite for interdisciplinary cooperation. Secondly, ethical reflections on the concepts' moral implications are only possible based on clear semantics (Scarano 2002; Wohlgenannt 1993). Thirdly, a reflected use of semantics is crucial for the

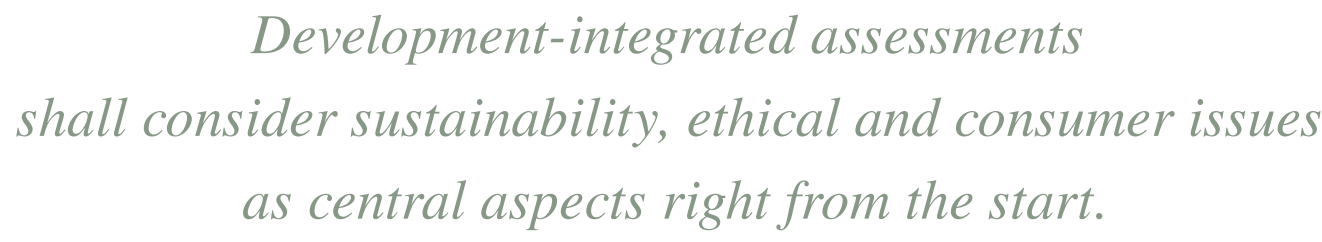

Against this background, the aim of this article is to present the approach of a development-integrated assessment, that both encourages and enables the innovators themselves to carry out assessments on sustainability, ethics and consumer issues as part of the innovation process. Based on a description of guiding principles for this new approach, practice-oriented tools for an early, interdisciplinary assessment within the innovation process are presented (Fig. 1).

The design, use and added value of these instruments in the field of basic research is illustrated using the Cluster of Excellence 'Living, Adaptive and Energy-autonomous Materials Systems' (livMatS) funded by the German Research Foundation (DFG) as an example of application. The vision of this cluster is to develop novel, bioinspired materials systems, which adapt autonomously to their environment and harvest clean energy from transdisciplinary opening, i. e. the easier, unprejudiced acceptance of the novel technologies by society. Insofar as novel technologies become a self-evident part of our environment, they also have an impact on the self-image and self-interpretation of the people into whose everyday life the novel technologies are integrated (Höfele 2020; Liggieri and Müller 2019).

Nevertheless, a reflection and evaluation of semantics should not be misunderstood as a limitation or restriction of interdisciplinary research, insofar as its concepts are subject to ethical evaluations. At the same time, new horizons open up when different concepts and semantics are confronted with each other. This happens precisely when, on the one hand, disciplines enter into a dialogue with each other and, on the other hand, when they enter into a transdisciplinary exchange with ethics, technology assessment and other societal groups. Such a fruitful ex- 
change is shown, for example, by the talk of adaptivity in biological, engineering and other societal contexts (Walther 2019). At the same time, this dialogue can also lead to a review and readjustment of ethical concepts, without touching basic ethical principles. Only in this way can ethical concepts respond adequately to the new scientific phenomena.

\section{Early warnings and early encouragement}

Moreover, assessment should not be limited to the identification and minimization of existing weaknesses and threats. It also needs to serve as a strategic radar on how to make optimal use of existing strengths and opportunities. Hence, in addition to an 'early warning system' an 'early encouraging system' should be part of the overall assessment architecture.

In order to integrate relevant sustainability issues into ongoing $\mathrm{R} \& \mathrm{D}$ activities, the assessment should take up and operationalize normative requirements of the 2030 Agenda (United Nations 2016) with its Sustainable Development Goals (SDGs) and the Planetary Boundaries (Rockström et al. 2009). Integrating societal and user benefits of potential target applications in existing indicator systems (e.g. VDI 2017) helps to substantiate and shape the strengths and opportunities of a R \& D object at an early stage. Concrete aspects for early warnings/encouragements derived from the normative background include:

- Substances that are part of the R \& D objects or are needed in laboratories for their processing

- Energy demand during manufacturing and use

- Recyclability in the end-of-life stage

With the help of additive manufacturing, formerly known as rapid prototyping, new insights and concepts can be visualized quickly and cost-effectively in technical demonstrators (Gibson et al. 2015; Wong and Hernandez 2012), though in some cases, this can have disadvantages. For instance, metal printing can have low levels of sustainability if not used for prototyping (Bierdel et al. 2019). Early warnings can portray and qualify the previously analytically determined strengths and weaknesses with a high degree of flexibility, adaptability and design freedom, making the early warning/encouraging system tangible.

\section{Embracing societal responsibility as part of the freedom of research}

Research requires freedom, but at the same time it should face up to its societal responsibility. In its memorandum containing 'Ten principles for freedom of science' the Alliance of Science Organisations in Germany clarifies that freedom of science even though it is a pillar of democracy - must not be confused with the absence of rules: "When conducting ethically sensitive research, scientists must always carefully weigh the opportunities against the risks their activities entail" (Alliance of Science Organisations in Germany 2019, p. 2). The responsible research and innovation (RRI) approach in the EU policy context (Owen et al. 2012), and the reflection framework described by Ferretti et al. (2016), for example, seek to meet this concern.

Any development-integrated TA that is obliged to sustainable development is strongly encouraged to consider relevant normative requirements mentioned above. As, inter alia, the "value sensitive design" approach has emphasized since the 1990s (Friedman and Hendry 2019), these normative principles must emerge from and be implemented at "pragmatic places", i. e. at locations relevant to technology assessment (Grunwald 1999, pp. 226, 228-232), which are characterized by specific interests, different moral requirements and goals. These must be weighed against each other and reconciled with each other. This, in turn, is only possible through a meta-discourse that follows generally acceptable moral principles that pay attention to the respective subjective demands and even embrace the respective discourses of interest.

Hence, it should also be part of the assessment to mirror these requirements and goals, develop appropriate metrics and indicators and make transparent any exceedance or deviations.

\section{Suitable tools for early engagement}

In the context of an assessment as early as possible, low Technology Readiness Levels (TRL) of the R \& D objects impose challenges on researchers, especially regarding the time-consuming aspect of data availability. Therefore, they require support through appropriate tools that operationalize the principles outlined above. As presented in figure 1, these tools facilitate the development-integrated assessment in a tiered approach called TAPAS ${ }^{1}$, beginning with a qualitative investigation that aims to pose the 'right' questions and is gradually refined with semi-quantitative and quantitative data in TRL-related iteration steps. The design and application of these tools in the field of basic research is described in the following, using the example of livMatS.

\section{Interdisciplinary online surveys}

$\mathrm{R} \& \mathrm{D}$ projects are often collaborative projects involving a broad range of disciplines and actors. Therefore, a better mutual understanding of the main areas of R \& D forms a crucial starting point, especially concerning the functions and possible applications. At the same time, it is key to raise awareness among all actors involved regarding sustainability and ethical issues associated with the R\&D objects, which must go hand in hand with agreements on the applied semantics.

In order to achieve these objectives, we propose to carry out a survey among all relevant actors at the lowest-possible TRL. In order to enable a comfortable processing as well as an efficient evaluation of results, the survey should be conducted on an online platform. In detail, the following aspects require rapid clarification and should be covered by such a survey:

1 Acronym for 'Tiered Approach for Prospective Assessment of Benefits and Challenges'. 


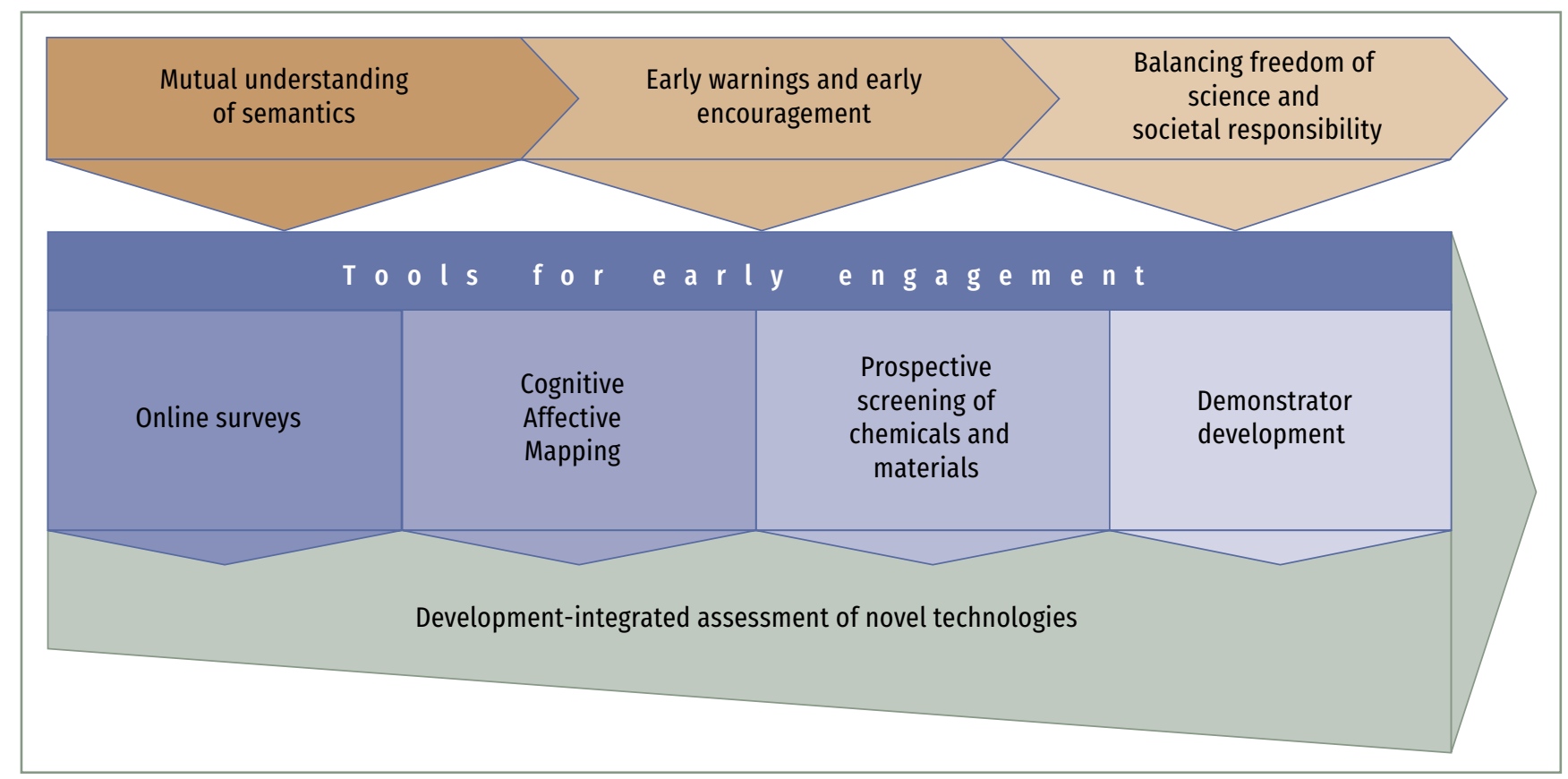

Fig.1: The principles of 'development-integrated assessment' and the tools implementing them in the development of novel technologies.

Source: authors' own compilation

- Identity of the used materials and substances

- Functions of the R \& D object

- Potential target application(s) or product(s)

- Type, functions and availability of planned demonstrators

- Investigation of potential user and societal benefits directly derived from the targets of the 2030 Agenda (e.g. increasing production of renewable energy, reducing waste generation)

- Dealing with interests and ethical challenges associated with the R \& D object, e. g. trade-offs between scientific, ecological, economic and social goals

In liv MatS the online survey was created using the standard software 'EFS survey'. All PhD researchers were invited to participate, the response rate reached $94 \%$. Covering the above-mentioned aspect, the survey revealed a detailed list of substances used in the laboratories that was directly used for a prospective screening of chemicals and materials (see below). While a survey of the chemicals and materials in use gives an "early warning", the examination of potential societal benefits provides "early encouragement" to make use of and further develop existing strengths. Moreover, concrete ideas and applications for demonstrators could be identified. An initial reflection on the perception of the blurring of the boundaries between natural and artificial properties also marks a first milestone regarding the interdisciplinary exchange on conceptual and ethical issues. Finally, the survey contributed to enhancing interdisciplinary exchange and networking within the cluster, creating mutual understanding of the different disciplines and broadening the basis of trust among all actors involved.

\section{Cognitive Affective Mapping}

To facilitate and expand exchange between experts and society, Cognitive-Affective Maps (CAMs) can be used to explore societal attitudes towards new technology developments and to report this back to the developers. Scientific studies have shown notable differences between the assessments and attitudes of laypersons and experts e. g. in risk perception (Digmayer and Jakobs 2016). An exchange between both groups is therefore appropriate from an ethical point of view and can provide new ideas for further technology development. A CAM is a kind of mind map in which concepts are not only related to each other, but also evaluated emotionally. CAMs were introduced by philosopher Thagard (2010) and proposed primarily for conflict resolution. In contrast to conventional questionnaires, CAMs offer the advantage of depicting complex interrelationships, including the intensity of the emotional valence of the concepts as well as supporting and inhibiting connections. Probands can create CAMs very freely or they could be given preset concepts for evaluation and arrangement. Especially the higher connection levels of a CAM are difficult to reach with questionnaire data. An innovative aspect of our work with CAMs is that we instruct participants online how to draw a CAM and thus collect large datasets. In this respect CAMs combine advantages of quantitative and qualitative approaches. Being a very versatile tool, they can be used for data collection, analysis and communication of results. While representing the complexity of individual and societal attitudes, they help to build bridges between science und society. In livMatS, CAMs have so far been used primarily to record attitudes and evaluations of laypersons re- 
garding various characteristics attributed to livMatS technologies. Our data can be collected online, with a software designed for it (Rhea et al. 2020).

\section{Prospective screening of chemicals and materials}

Since the development of novel technologies is usually associated with the use of chemicals and materials, their early assessment is of paramount importance. Within this context, the 'REACH Radar' tool of Bunke et al. (2017) can serve as an early warning system at low TRLs. Although primarily addressing companies, the freely available tool can also be easily used by
(Moultrie 2015). They can also be used as periodic 'snapshot in time' system-level demonstrations of developed technologies (Ross 2003) and to identify promising configurations and associated technology drivers, as well as providing comprehensive conceptual systems analyses (Jimenez et al. 2011).

Technological demonstrators for low TRLs can be used as response tools to directly implement new ideas, requirements or specifications that may arise as a result of the above presented tools. For example, a CAM survey may reveal that a different appearance would be more conducive to improved customer and public acceptance of a product/system; during interviews with experts unforeseen requirements to the object may arise, TAPAS

\section{Low-threshold instruments interlinked with each other provide added value and can open new 'pathways of innovation'.}

researchers or civil society actors. It enables the user to identify hazardous properties of the applied substances that could lead to existing or future restrictions according to the EU chemicals regulation REACH aiming to replace Substances of Very High Concern (SVHC) with less hazardous substitutes.

Setting a focus on SVHC, REACH Radar provides a comprehensive review of whether the used substances are listed in REACH Annex XIV (substances requiring authorization) or are candidates for the inclusion in Annex XIV. If substances are becoming subject to an authorization procedure under REACH because of their hazardous properties, they may no longer be available in a few years' time. If such substances are identified, a review is carried out in order to explore existing substitution options.

In livMatS, REACH Radar was applied as second iteration step within the TAPAS framework, evaluating more than 200 substances that were specified in the online survey (see above). For some of these substances, the analysis revealed a need for observation or action in the future. These substances will be subject to a more detailed assessment in the next iteration steps of TAPAS. Furthermore, a criticality assessment of the relevant metallic raw materials is carried out on the basis of available material inventories, assessing supply risks and vulnerability as well as ecological aspects.

\section{Demonstrator development}

Technological demonstrators are generally used as proof of concepts for future products that can be used to make a technical principle or system tangible in order to support communication within and outside the scientific community. Produced with additive manufacturing technologies, demonstrators can showcase scientific principles, possible applications as well as their feasibility and performance to investors, collaborators and funders may indicate a different base material more advantageous for the device's sustainability and recyclability.

Within livMatS many of these advantages are exploited within the artificial Venus flytrap (AVFT) demonstrator. The aim is to develop an AVFT that resembles the biological model not only in appearance but also in function (Esser et al. 2019; Esser et al. 2020) and spin off emerging technology to novel products (as flexible solar harvesters). The livMatS AVFT as a demonstrator platform enables a direct and research near implementation of novel concepts and alternative materials indicated by REACH Radar. Additionally, these systems further the inter- and transdisciplinary communication and collaboration between the research areas (biology, biomimetics, chemistry, engineering, informatics, philosophy, ethics, psychology, physics and robotics) and other societal groups as all findings are implemented within one system.

\section{Conclusion and outlook}

In this paper we have described guiding principles and concrete tools that allow a development-integrated assessment within the TA framework at an early stage. By their application in the innovation process these principles and instruments inevitably cause a deceleration of technology development. However, by integrating TA into the origin of innovation and encouraging the innovators to carry out robust assessments, the reaction capacity of science to the challenges of the Great Acceleration can be increased substantially. This intentional pause can shorten society's overall reaction time since it helps to identify and avoid undesirable technological developments as early as possible. Although it may seem paradoxical, the development-integrated approach can thereby accelerate the development of sustainable technol- 
ogies, because early warnings help to identify risks in due time and early encouragements foster to open up and chart pathways for innovation that enable positive and sustainable contributions to societal objectives (such as the SDGs).

However, existing challenges and limitations of the described approach need to be tackled. Besides data availability, trust plays a vital role - both within and outside the scientific community. Internally, continuous and transparent communication of the methodical approach for assessment and the results generated by the applied tools is considered to be key. In order to foster exchange with and inclusion of society, CAMs can provide valuable contributions to the exploration of societal attitudes towards new technologies. Furthermore, demonstrators can be used to make new technologies tangible for society and its moral claims, and to support communication within and outside of the scientific community. Once the R \& D objects have reached higher TRLs, these aspects could be further explored in 'real world laboratories' in order to foster transdisciplinary cooperation between science and society. In this sense, the encouragement of transparent exchange within an interdisciplinary research team as well as with society can contribute to mutual trust and acceptance.

The applicability of the presented tools for very low TRL that are inherent to basic research has been verified using the DFG Cluster of Excellence livMatS as an example of application. In livMatS, basic research is already linked with sustainability, ethics and consumer issues in a tiered approach. Experience gained in this context shows that low-threshold instruments interlinked with each other provide added value and stimulate interdisciplinary exchange regarding sustainability, ethics and consumer issues at a very early stage. For example, the demonstrator platform can be used to investigate the feasibility of SVHC substitutes identified within the REACH Radar tool. Furthermore, the demonstrators can take up the findings regarding acceptance of living materials systems resulting from CAMs and highlight how users and society can benefit from such novel products and system developments by taking their values into account. This can open new 'pathways of innovation' and produce technologies contributing to a sustainable development (e. g. personalized energy harvesting systems based on flexible materials) that would otherwise not have been recognized.

\section{Funding declaration}

Funded by the Deutsche Forschungsgemeinschaft (DFG, German Research Foundation) under Germany's Excellence Strategy - EXC-2193/1 - 390951807.

\section{References}

Abels, Gabriele; Bora, Alfons (2013): Partizipative Technikfolgenabschätzung und -bewertung. In: Georg Simonis (ed.): Konzepte und Verfahren der Technikfolgenabschätzung. Wiesbaden: Springer, pp. 109-128. https://doi. org/10.1007/978-3-658-02035-4_7

Alliance of Science Organisations in Germany (2019): Final memorandum of the campaign freedom is our system. Available online at: https://wissenschaftsfreiheit.de/wp-content/uploads/2019/09/Final-
Memorandum-of-the-campaign-Freedom-is-Our-System.pdf, last accessed on 07. 01.2021.

Bierdel, Marius et al. (2019): Ökologische und ökonomische Bewertung des Ressourcenaufwands. Additive Fertigungsverfahren in der industriellen Produktion. Berlin: Self-published. Available online at: https://www.ressourcedeutschland.de/fileadmin/user_upload/downloads/studien/VDI_ZRE_ Studie_Additive_Fertigungsverfahren_bf.pdf, last accessed on 07.01.2021. Bunke, Dirk et al. (2017): Reach radar network. Systematic identification and prioritisation of substances of very high concern for the group of galvanisation companies. Freiburg: Öko-Institut e. V. Tool available online at: https:// www.oeko.de/reach-radar, last accessed on 07.01.2021.

Digmayer, Claas; Jakobs, Eva-Maria (2016): Risk perception of complex technology innovations. Perspectives of experts and laymen. In: Proceedings of IEEE International Professional Communication Conference, 9 p. https://doi. org/10.1109/IPCC.2016.7740510

Esser, Falk et al. (2019): Adaptive biomimetic actuator systems reacting to various stimuli by and combining two biological snap-trap mechanics. In: Uriel Martinez-Hernandez et al. (eds.): Biomimetic and biohybrid systems. $8^{\text {th }}$ international conference. Cham: Springer, pp. 114-121. https://doi. org/10.1007/978-3-030-24741-6_10

Esser, Falk; Auth, Philipp; Speck, Thomas (2020): Artificial venus flytraps. A research review and outlook on their importance for novel bioinspired materials systems. In: Front. Robot. Al 7: 75, 13 p. https://doi.org/10.3389/ frobt.2020.00075

Ferretti, Johanna et al. (2016): Reflexionsrahmen für Forschen in gesellschaftlicher Verantwortung. BMBF-Projekt „LeNa - Nachhaltigkeitsmanagement in außeruniversitären Forschungsorganisationen“. Berlin: LeNa. Available online at: https://www.nachhaltig-forschen.de/fileadmin/user_upload/ Reflexionsrahmen_DRUCK_2016_09_26_FINAL.pdf, last accessed on 07. 01.2021.

Friedman, Batya; Hendry, David (2019): Value sensitive design. Shaping technology with moral imagination. Cambridge: MIT Press. https://doi.org /10.1080/17547075.2019.1684698

Gibson, Ian; Rosen, David; Stucker, Brent (eds.) (2015): Additive manufacturing technologies. New York: Springer. https://doi.org/10.1007/978-1-4939-2113-3_17

Gleich, Arnim von (2013): Prospektive Technikbewertung und Technikgestaltung zur Umsetzung des Vorsorgeprinzips. In: Georg Simonis (ed.): Konzepte und Verfahren der Technikfolgenabschätzung. Wiesbaden: Springer, pp. 51-73. https://doi.org/10.1007/978-3-658-02035-4_4

Grunwald, Armin (1999): Ethische Grenzen der Technik? Reflexionen zum Verhältnis von Ethik und Praxis. In: Stephan Saupe and Armin Grunwald (eds.): Ethik in der Technikgestaltung. Praktische Relevanz und Legitimation. Berlin: Springer, pp. 221-252. https://doi.org/10.1007/978-3-642-60033-3_11

Grunwald, Armin (2010): Technikfolgenabschätzung. Eine Einführung. Berlin: edition sigma. https://doi.org/10.5771/9783845271057

Grunwald, Armin (2019): Technology assessment in theory and practice. New York: Routledge. https://doi.org/10.4324/9780429442643

Höfele, Philipp (2020): New technologies and the 'heuristics of fear'. The meaning and prehistory of an emotion in Jonas, Heidegger and Hegel. In: Hungarian Philosophical Review 64, pp. 166-182.

Jimenez, Hernando; Schutte, Jeffery; Mavris, Dimitri (2011): System readiness and risk assessment for advanced vehicle concepts. Discussion of fundamental concepts. In: Proceedings of $49^{\text {th }}$ AIAA Aerospace Sciences Meeting including the New Horizons Forum and Aerospace Exposition. Orlando, Florida: 
American Institute of Aeronautics and Astronautics, 04.-07.01.2011, 18 p. https://doi.org/10.2514/6.2011-423

Liggieri, Kevin; Müller, Oliver (eds.) (2019): Mensch-Maschine-Interaktion. Handbuch zu Geschichte - Kultur - Ethik. Berlin: Springer. https://doi. org/10.1007/978-3-476-05604-7

livMatS - Living, Adaptive and Energy-autonomous Materials Systems (2020): Materials systems of the future. Available online at https://www.livmats.unifreiburg.de/en, last checked on 07.01.2021.

MacLeod, Miles (2018): What makes interdisciplinarity difficult? Some consequences of domain specificity in interdisciplinary practice. In: Synthese 195, pp. 697-720. https://doi.org/10.1007/s11229-016-1236-4

Moultrie, James (2015): Understanding and classifying the role of design demonstrators in scientific exploration. In: Technovation 43-44, pp. 1-16. https://doi.org/10.1016/j.technovation.2015.05.002

Owen, Richard; Macnaghten, Phil; Stilgoe, Jack (2012): Responsible research and innovation. From science in society to science for society, with society. In: Science and Public Policy 39 (6), pp.751-760. https://doi.org/10.1093/ scipol/scs093

Rhea, Carter; Reuter, Lisa; Piereder, Jinelle (2020): Valence software release. https://doi.org/10.17605/OSF.IO/9TZA2

Rockström, Johan et al. (2009): A safe operating space for humanity. Nature 461 (7263), pp. 472-475. https://doi.org/10.1038/461472a

Ross, William (2003): The impact of next generation test technology on aviation maintenance. In: Proceedings of Autotestcon. IEEE Systems Readiness Technology Conference, Anaheim, CA, U.S.A., 22.-25. 09.2003, pp. 2-9. https:// doi.org/10.1109/AUTEST.2003.1243547

Scarano, Nico (2002): Metaethik. Ein systematischer Überblick. In: Marcus Düwell, Christoph Hübenthal and Micha Werner (eds.): Handbuch Ethik. Stuttgart: Metzler, pp. 25-35.

Steffen, Will; Broadgate, Wendy; Deutsch, Lisa; Gaffney, Owen; Ludwig, Cornelia (2015): The trajectory of the Anthropocene. The Great Acceleration. In: Anthropocene Review 2 (1), pp. 81-98. https://doi.org/10.1177/2053019614564785

Steffen, Will; Grinevald, Jacques; Crutzen, Paul; McNeill, John (2011): The Anthropocene. Conceptual and historical perspectives. In: Philosophical transactions of the Royal Society A 369 (1938), pp. 842-867. https://doi.org/10.1098/ rsta.2010.0327

Thagard, Paul (2010): EMPATHICA. A computer support system with visual representations for cognitive-affective mapping. In: K. McGregor (ed.) Proceedings of the workshop on visual reasoning and representation. Menlo Park, CA: AAAI Press, pp. 79-81), 11.-15. 07.2010.

United Nations (2016): Report of the inter-agency and expert group on sustainable development goal indicators. Available online at: https://unstats.un.org/ unsd/statcom/48th-session/documents/2017-2-IAEG-SDGs-E.pdf, last accessed on 07.012021.

VDI - Verein Deutscher Ingenieure (2000): VDI Richtlinie 3780. Technology assessment. Concepts and foundations. Berlin: Beuth.

VDI (2017): VDI Richtlinie 4605. Evaluation of sustainability. Berlin: Beuth.

Walther, Andreas (2019): Viewpoint. From responsive to adaptive and interactive materials and materials systems. A roadmap. In: Advanced Materials 32, Al 1905111. https://doi.org/10.1002/adma.201905111

Warschat, Joachim; Schimpf, Sven; Korell, Markus (eds.) (2015): Technologien frühzeitig erkennen, Nutzenpotenziale systematisch bewerten. Methoden, Organisation, semantische Werkzeuge zur Informationsgewinnung und -speicherung. Ergebnisse des Verbundforschungsprojekts synctech - synchro- nisierte Technologieadaption als Treiber der strategischen Produktinnovation. Stuttgart: Fraunhofer Verlag.

Wohlgenannt, Rudolf (1993): Philosophische Betrachtungen und Wissenschaftstheoretische Analysen. Vienna: Springer. https://doi.org/10.1007/978-1-48993780-3

Wong, Kaufui; Hernandez, Aldo (2012): A review of additive manufacturing. In: ISRN mechanical engineering, AI 208760. https://doi.org/10.5402/2012/208760

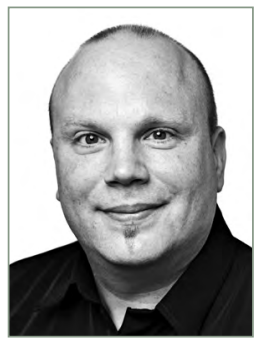

\section{MARTIN MÖLLER}

is a doctoral researcher at livMatS since 2019. Additionally, he has been working as senior researcher at Öko-Institut since 2002. With his background as an environmental engineer he is engaged in sustainability assessment of emerging materials and technologies, both at the national and international level.

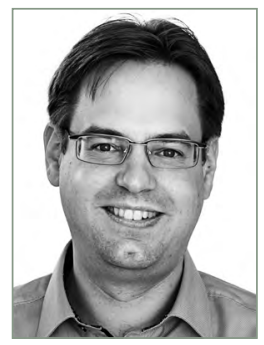

\section{DR. PHILIPP HÖFELE}

is a postdoctoral researcher at livMatS since 2019. Additionally, he works as a lecturer at the Freiburg Department of Philosophy. He is specialized in the philosophy of nature and technology as well as practical philosophy and ethics with a historical focus on the philosophies of the 19th and 20th centuries.

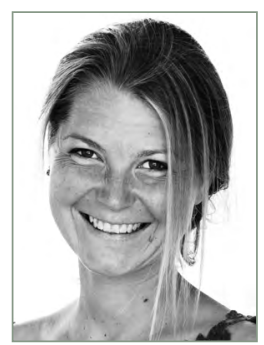

\section{LISA REUTER}

is a doctoral researcher at livMatS since 2019, after she completed her studies in psychology. In her work she explores possible applications for the method Cognitive-Affective Mapping for psychological and interdisciplinary topics.

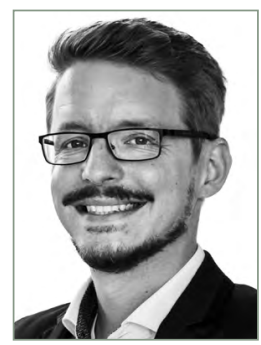

\section{DR. FALK J. TAUBER (NĖ ESSER)}

is a postdoctoral researcher at the livMatS since 2019 coordinating the demonstrator development. He studied biology at the RWTH Aachen University specializing in biomimetics and neurobiology. During his studies and PhD at the University of Freiburg he developed various biomimetic demonstrator systems.

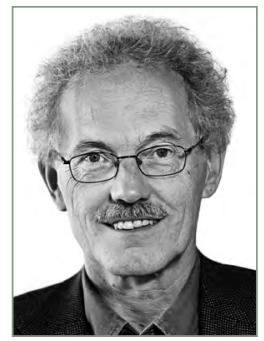

\section{PROF.DR. RAINER GRIESSHAMMER}

is a principal investigator researcher at livMatS since 2019. He studied chemistry and was head of the Öko-Institut for three decades. He is specialized in product sustainability assessment and transformations. 